Literature Reviews

\title{
Impact of Building Function on Thermal Comfort: A Review Paper
}

\author{
Mamdooh S. Alwetaishi \\ Department of Civil Engineering, Taif University, City, Saudi Arabia
}

Article history

Received: 23-08-2016

Revised: 06-10-2016

Accepted: 14-10-2016

Email:

alwetaishi.mamdooh@hotmail.com

\begin{abstract}
One of the most problems for achieving thermal comfort in buildings is disregarding the impact of different types of building use. They are differ depending on the activity style they perform inside. In residential buildings, for instance, variations in indoor temperature is more acceptable than the case in hotels or hospitals. This review is leading to seek a solution for this problem which usually found neglected. Consequently, the selection of the reviewed papers was based on building use. Main factors affecting thermal comfort will be discussed. In addition, focus on the effect of building's function on thermal comfort such as residential buildings, office buildings, heath care buildings and educational buildings. As far as environmental aspects affecting thermal comfort, air temperature was found to be the most effective one among the rest. Moreover, the effect of building function on adaptive thermal comfort has been discussed with reference to residential, office, healthcare and educational buildings. It has to be considered that there is a noticeable effect on the different types of building in terms of its impact on the users.
\end{abstract}

Keywords: Thermal Comfort, Review Paper, Thermal Comfort in Building, Educational Buildings, Office Buildings

\section{Introduction}

Having the right temperature indoors was and still one of the most remarkable things that people concern about in buildings. Thermal comfort is a general term which used to describe people's state and condition. It has many definitions as it has been mentioned by Djongyang et al. (2010) as "a state in which there are no driving impulses to correct the environment by the behaviour". However, the most common definition is the one which has been announced by the American Society of Heating, Refighting and Air-Conditioning Engineers (ASHRAE) defined as "the condition of mind in which satisfaction is expressed with thermal environment".

Thermal comfort is mostly a state of mind rather than a state of condition as Kuchen and Frsch (2009) has found that a person who is staying in the same space, climate and culture could have different state to thermal comfort with another one who is staying identically at the same variables. Similarly, Djongyang et al. (2010) has expressed the same fact which shows that achieving thermal comfort can be affected not only by environmental factors, but also social, culture and other aspects have relative attributions (Djongyang et al., 2010). Moreover, the International Standards ISO-7730
(2005) considered that since there is an individual differences, it is not an easy task to specify the thermal comfort, but it is possible to modify the environment to be accepted by certain percentage of the occupants. This percentage has been estimated by $80-90 \%$ of the occupants (ISO-7730, 2005). Although there are many publications related to thermal comfort, there is still a gap in thermal comfort studies in the relation to interdisciplinary work. Considering psychologies, physiologist, sociologist, philosophers and also with other building related subjects such as architects and engineers (Ricardo et al., 2015).

There are many reasons why the society should concern and consider thermal comfort. There is also an international consensus to cut down carbon emissions (Tian et al., 2011). Although it might be difficult in some climatic regions to achieve thermal comfort without the use of fossil fuels (Talyor et al., 2008), it is possible to achieve thermal comfort for the most of the year in certain locations with utilizing the use of thermal comfort strategies (Memon et al., 2008).

Health is one of the most important aspects that are affected by thermal comfort, "Thermal comfort is not just about ensuring a sensation of a satisfaction with ambient temperature, it is inextricably linked to health" 
(Ormandy and Ezratty, 2012) has pointed out that if the outdoor temperature was not appropriate to the core temperature $\left(37^{\circ} \mathrm{C}\right)$, the body whether will sweat to cool the skin in the case of hot environment, or will be shivering in the case of cold which is an indication of warning (Sakka et al., 2012). In addition, Parsons (2002) has reported that if the temperature goes higher than $30^{\circ} \mathrm{C}$ in classrooms, this could affect student's ability and work (Parsons, 2002).

Furthermore, Cheong et al. (2003) has noted that the most important aim of conditioning indoors is to provide a comfortable and healthy environment for the users. Furthermore, Atmaca et al. (2007) has indicates that good building design has to provide health and safety to the occupants.

It has to be highlighted that thermal comfort in indoor environment is one of the comfort standards required for the users. Thus, there are some other comforts which should be taken into consideration in order to achieve better satisfaction and healthy indoor environment such as daylighting comfort and visual comfort.

Based on what have been discussed, thermal comfort should receive more attention from researchers as Hall et al. (1999) has reported Fanger's state in his most important book in thermal comfort that there is no enough knowledge about it for practice application.

\section{Thermal Comfort Estimation Approaches}

Nowadays, there are two main approaches to estimate human thermal comfort Predicted Mean Vote (PMV) and the Percentage of Dissatisfied (PPD) (Backer and Paciuk, 2009; Homod et al., 2012). These approaches based on Fanger's work which take into account some environmental aspects such as dry bulb temperature, humidity, air velocity and mean radiant temperature (Fig. 1 and 2) as well as human factors such as thermal resistance and metabolic rate (Jang et al., 2007). Thermal balance is derived when the internal heat production in the body is equal to the heat loss to the surrounding environment (ISO-7730, 2005). There is abounding papers that have been published to investigate and validate these methods as standards that can be applied worldwide. However, there were many results which against them, but they still have a good contribution to be the most commonly used approaches for thermal comfort arithmetic as Jang et al. (2007) has pointed out that they are a suitable method which have the ability to describe the user's reaction about their comfort.



Fig. 1. The most important environmental factors affecting thermal comfort



Fig. 2. Aspects affecting the assumption of thermal comfort in the two approaches (PMV and PPD) 


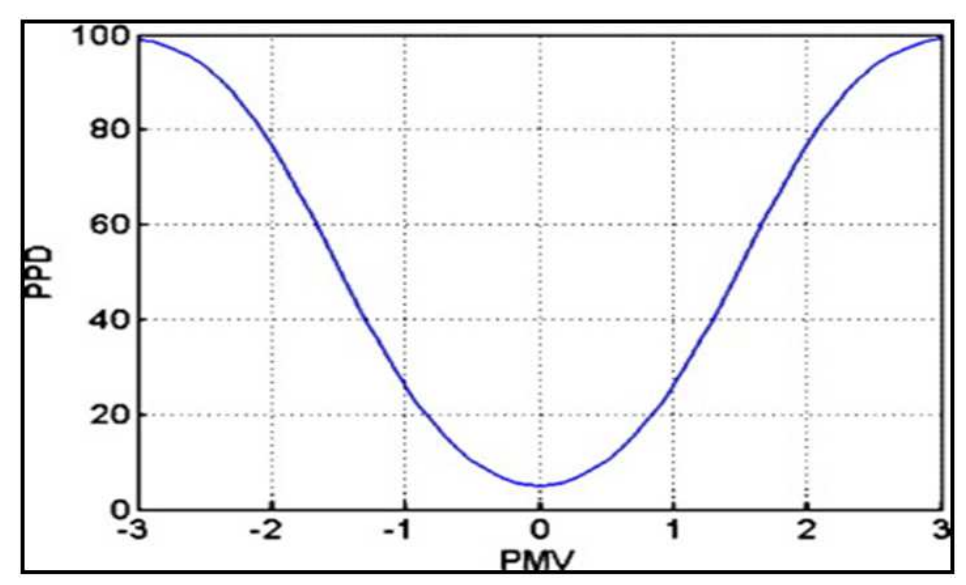

Fig. 3. Relationship PMV versus PPD

In terms of PMV it can be defined as it has been mentioned "PMV is an index that predicts the mean value of votes of a large group of persons on the 7-point thermal sensation scale" (ISO-7730, 2005), where the range of the scale as follow: +3 is too hot, +2 is warm, +1 is slightly warm, 0 is neutral, -1 is slightly cool, -2 is cool and -3 is cold. In addition to that PMV model uses heat balance methods to combine the six factors to calculate the state of thermal comfort for the users (ASHRAE-55, 2004).

As far as PPD is concerned, it has been defined by ISO-7730 (2005) as "The PPD predicts the mean value of the thermal of a large people" it is related to the PMV model (Ricardo et al., 2016), but it is expressed by those who feel discomfort $(+2$ and +3 or -3 and -2$)$ (ASHRAE-55, 2004). It has been established to determine the percentage of thermally dissatisfied people who is feeling too hot or too cool.

PMV in many publications was found to be misleading when comparison with actual state of thermal comfort (Liu et al., 2014; Mustapa et al., 2016). It work more accurate in the operation of air conditioning. However, adaptive comfort models tend to have wider range of comfort temperatures, thus, it will have considerable amount of energy consumption (Fig. 3 shows the between Relationship PMV versus PPD).

\section{Factors Affecting Thermal Comfort}

Part from the individual elements that have relative influence on thermal comfort, there are several factors that have the major impact on the satisfaction or dissatisfaction of the occupants.

The most affective factors on human thermal comfort are the environmental factors which cover many aspects which have to be taken into account. However, the consideration of each one has received certain concern. (ASHRAE-55, 2004) and (Parsons, 2002) have pointed out the following factors as the most important when addressing thermal comfort air temperature, humidity, radiant and air movement which are considered as environmental factors. In addition to that are metabolic rate which is generated by human activity and body insulation which is clothing. However, some sources are expressing extra factors in group's format showing priority for some of the factors. This is as it has been pointed out by Gadi in Hall (2010). Gadi has divided the factors in two different groups the first one contain metabolic rate, mean radiant temperature, air velocity, clothing thermal resistance, air temperature and vapour pressure whereas the second group contains sweat rate, skin wittiness, clothing fit, skin temperature, clothing wittedness and clothing surface.

\section{Air Temperature}

According to Health and Safety Executive (HSE), air temperature is the temperature surrounding the body it can be in degree Celsius or Fahrenheit. When talking about air temperature, it is mean the most affective aspect in the entire environmental factors. This is because human being is very sensitive to temperature (Hanqing et al., 2006). This become very obvious when people would like to have a short break, for instance, the first question comes to mind about that place in terms of weather is 'temperature'. In a studies done by (Metje et al., 2008) and (Hoof and Hensen, 2007) indicate that air temperature is one of the most important aspects in addressing thermal comfort. Moreover, Parsons (2002) has state the fact that higher temperature in classrooms (above $30^{\circ} \mathrm{C}$ ) may have an effect on the ability of the students as well as their achievements during the class (Parsons, 2002).

As far as the optimum indoor temperature is concerned, Fanger has recommended an optimal indoor temperature for human thermal comfort to be $25.6^{\circ} \mathrm{C}$ Celsius in Northern temperate zone. On the other hand, other has recommended $27^{\circ} \mathrm{C}$ Celsius with $(80 \%)$ relative 
humidity and $0.4 \mathrm{~m} \mathrm{sec}^{-1}$ air velocity (Jang et al., 2007). In fact, both of the suggested figures can be appropriate when applying the variation of relative humidity and air velocity as they play a major role in determining the optimum indoor temperature.

Furthermore, people can accept wide range of temperature when considering adaptation which can bring the average of air temperature to higher levels. In a study was done by Wang et al. (2010) which is evaluating the comfort level of the Harbin's occupant. The author has found that in the temperature of $23.7^{\circ} \mathrm{C}$ and cloth insulation of $0.54 \mathrm{col}, 80 \%$ of the occupants have accepted the air temperature range of $21.5-31.0^{\circ} \mathrm{C}$ which is well below and above the average that has been determined in the international standards. The average in the international standards has the range from 24 to $28^{\circ} \mathrm{C}$ (Wang et al., 2010).

\section{Radiant Temperature}

It is the heat that radiates from a heated object which is existing in the environment. In some cases, this aspect could have a greater influence than air temperature itself. Sun could be the most important radiated object that could be taken into account. However, there are several examples as well such as cookers, dryers, hot surfaces and ovens (HSE, 2012).

The figure is indicating the effect of worming or cooling the walls and ceilings in increasing the discomfort in buildings. It can be noted that warming or cooling the ceiling and cooling the wall could have a significant impact on the occupant's dissatisfaction whereas warming the wall is the only case which has less.

In terms of the ceiling, there were no noticeable differences between the cooling and warming, but there was a clear difference in the case of the wall. A possible explanation for this is that there is no direct solar radiation in the case of cooling; the cool cases heat loss from the building. On the other hand, warming the wall and ceiling could add direct solar radiation on the ceiling which will increase the heat radiated into a building.

The use of radiation can be utilized to be natural and clean if the building was design from an early stage to control the solar radiation. In a study conducted by (Memon et al., 2008) has concluded that it is possible to achieve thermal comfort for most of the time over the year. However, in the case of hot locations the solar radiation that is generated from the sun or even any other source of radiation has to be controlled and blocked based on the climatic condition in the region. This without any doubt could lead to thermal discomfort (Atmaca et al., 2007).

\section{Humidity}

According to ISO-7730 (2005), humidity is the absolute humidity expressed as water vapour pressure in the air which influences the evaporation heat loss from a person. If water is heated and had evaporated the surrounding area, it will increase the percentage of humidity at the air. Relative humidity is the percentage between the current amount of evaporative water and the actual amount of water that the air can hold at a given air temperature (Liu et al., 2014).

In terms of the impact of the humidity, it is very connected to the current air temperature in the environment as well as the air speed which allow the skin to loss heat. However, when the relative humidity is between $40-70 \%$ it would not have a considerable effect on human comfort (Liu et al., 2014). However, ASHRAE 44 has pointed out that there is no established lower humidity for thermal comfort. This is because humidity as such dose not clarifies the state of the occupants, more aspects have to be taken into account as well (ASHRAE-55, 2004).

High humidity in hot regions is a major problem since it will prevent skin sweating in order to cool the skin. Parsons (2002) has expressed the importance of sweating when the body temperature rises; sweat is the main and most effective method to cool the skin when evaporation takes place (Sakka et al., 2012). ISO 7730 has drawn attention to the approvable humidity range. At a moderate temperature $\left(26^{\circ} \mathrm{C}\right.$ and more $)$ with moderate activity (about 2 met), having high or even moderate humidity could lead to occupant's discomfort. In addition to that the same standard has added thermal sensation, wetness, skin dryness and eye irritation to the list of variables affecting sweating ISO-7730 (2005).

\section{Air Velocity}

It has been defined as "The speed of air moving across the worker and may help cool the worker if it is cooler than the environment" (Liu et al., 2014). Air velocity is quite important factor as people are very sensitive to it. As a result, it could lead to cooling or heating the space based on the given indoor condition such as indoor temperature and relative humidity. Those two factors and air speed have the most effect on human thermal comfort indoors (Hall, 2010). The key point in air velocity is that it influences the convective heat exchange between a person and the environment which as a result will affect the general heat loss ISO-7730 (2005). This relationship relies heavily on the temperature and the relative humidity in the surrounding environment.

With regarding the limit of indoor air velocity, ASHRAE 44 has state that the relation between air speed and improvable comfort has not established yet. But, modifying air speed indoors allows more acceptable temperature under certain conditions. Even through this standard has not given a fixed number as a limit, it gave a suggested highest indoor air speed which as high as $0.2 \mathrm{~m} \mathrm{sec}^{-1}$. Based on experience, having higher than $0.2 \mathrm{~m} \mathrm{sec}^{-1}$ indoors could lead to disturbance even if the indoor air temperature is high and the need of skin 
convective with the environment is essential (ASHRAE-55, 2004). Furthermore, ISO 7730 has taken into consideration that there is no fixed minimum air velocity indoors, because this will rely strongly on the other variables, so that the air velocity could sometimes be zero or very close to that and occupants could be satisfied.

\section{Activity}

Activity is one of the main factors that are affecting thermal comfort. There are many types of buildings and each one has its own purpose and level of activities required. As a result, the activity of people in schools is different from that one in offices which will lead to major differences in thermal sensation. It can be defined as "heat that we produce inside our bodies as we carry out physical activity" (Mustapa et al., 2016). The more active we are, the more heat we produce. Consequently, more heat has to be lost from our bodies, so that we do not feed discomfort.

ISO-7730 (2005) has indicated that difference of 0.1 met might result production of a thermal sensation equals to that produced by $1{ }^{\circ} \mathrm{C}$ in air temperature. In the same way, difference of 0.4 met could lead to 2.5 to $3^{\circ} \mathrm{C}$ in air temperature. This show clearly how effective having variety of activates indoors which could lead to over warmth or coolness in different conditions. Furthermore, in a study of Rowe (2001) found that when air and mean radiant temperature are identical at $24^{\circ} \mathrm{C}$ and air velocity is $0.41 \mathrm{~m} / \mathrm{s}$, relative humidity is $43 \%$ and body insulation is 0.7 clo. A person with activity rate of 1.2 met can be expected by the Production Mean Vote (PMV) to feel natural. However, with metabolic rate of 1.6, the PMV would be far from the comfort limit recommended.
Fig. 5 shows the differences in the metabolic rate in (ASHRAE-55, 2004; ISO-7730, 2005) standards for some sort of activates that are quite common. The heat produces from our activities increase with our paten in life. Reclining, for instance, could be considered as one of the lowest heat producers after sleeping as there is no work that could lead to hear emissions. In addition, there is no major difference between the two standards except in the light standing activates and this is understandable since there is wide range of standing activities that may lead to some differences in the heat production.

\section{Clothing Insulation}

In prehistoric time man used to use animal's furs to protect him from cold (Caril et al., 2007). Both clothing and skin can be considered as the body's insulation which protects it from the environment. Oliveira et al. (2011) has indicated that the assessment of the thermal insulation of clothing is quite important as far as the study of human thermal exists. With regard to clothing insulation it provides a thermal resistance between the body and the environment. It also keeps the body in an acceptable thermal state with respect of different climates.

There are many functions for clothing that could play a major role, 'fashion', for example is one of which (Sakka et al., 2012). Similarly, Caril et al. (2007) has shared the same idea; he reported that clothing has become a way to express ourselves in community. Moreover, Lee and Choi (2004) has pointed out that energy consumption was higher with lighter clothing than heavier one during the cold climates. This mater should receive more attention as it leads to energy expenditure, particularly, with women as the study has indicated.

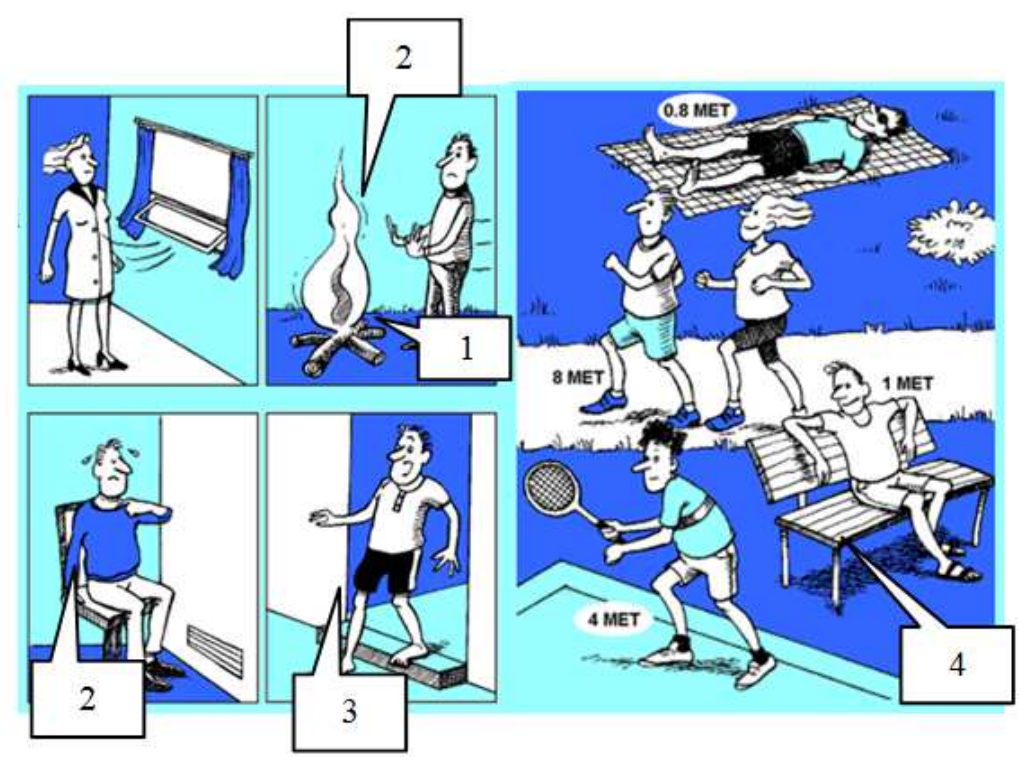

Fig. 4. Local thermal discomfort; 1. Cooling or heating of parts of the body by radiation. This is known as a radiation asymmetry problem; 2. Cold feet and a warm head at the same time, caused by large vertical air temperature differences; 3 . Hot or cold feet, caused by uncomfortable floor temperature; 4. Metabolic estimation rate; Source: ANNOVA thermal comfort (n.a) 


\section{Metabolic Rate}

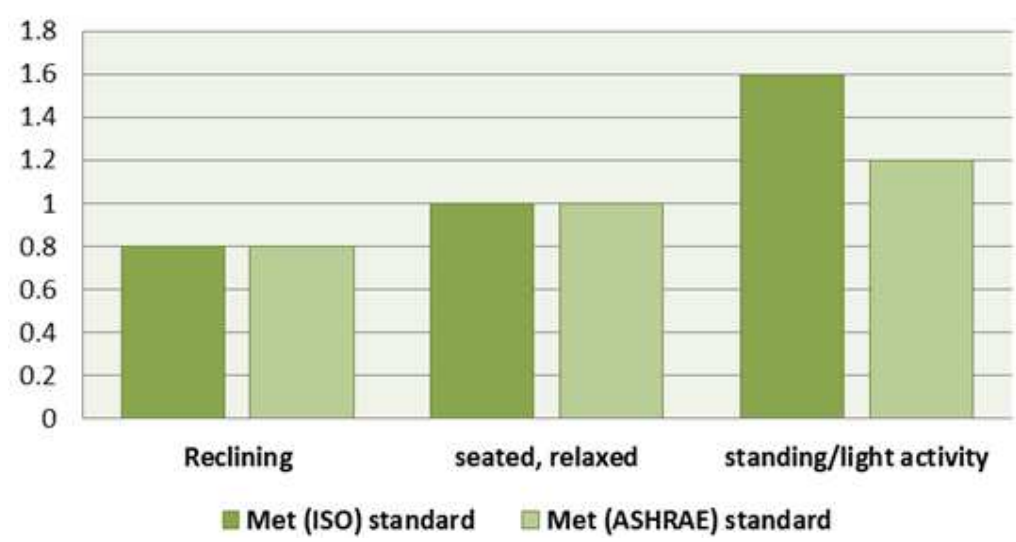

(a)

\section{Metabolic Rate}

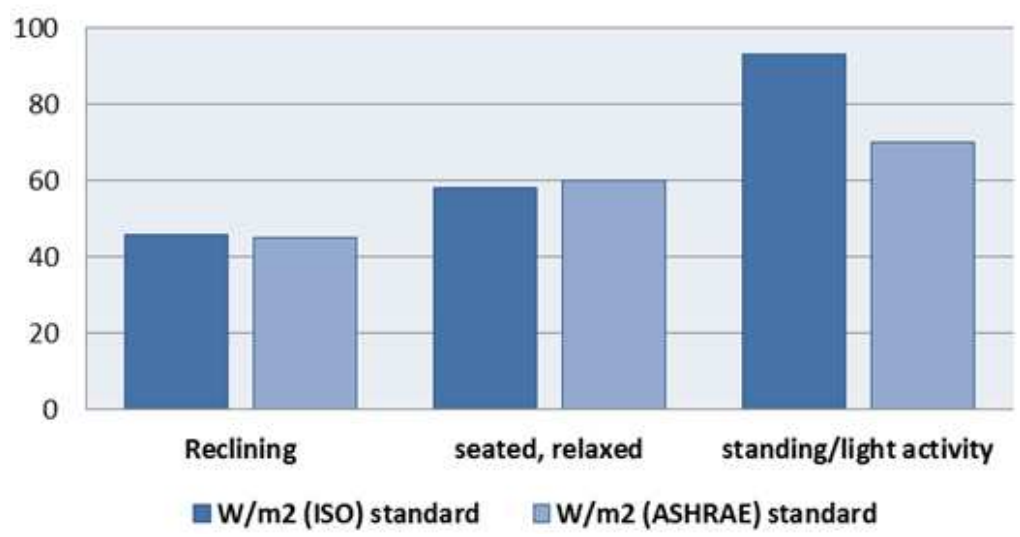

(b)

Fig. 5. (a) Metabolic rate of common activities for both ISO-7730 and ASHRAE 44 standards indicated by Met; (b) Figure 4.8. Metabolic rate of common activities for both ISO 7730 and ASHRAE 44 standards indicated by W/m²

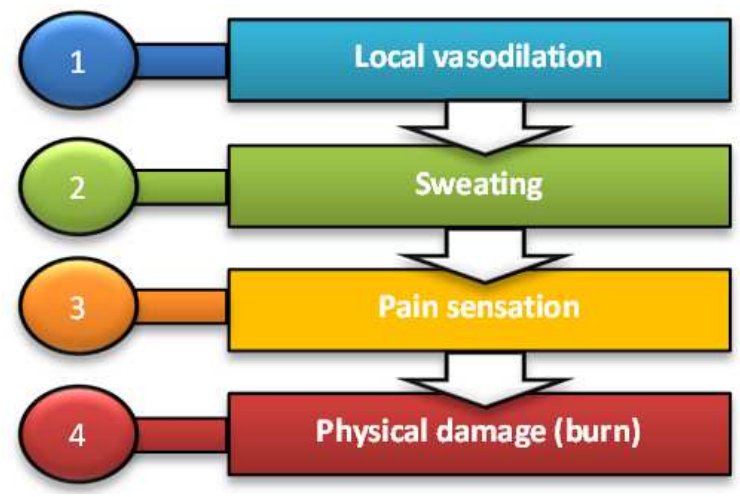

Fig. 6. Heat levels affecting the skin. Source: Parsons (2002)

In Gulf countries a traditional Arabian clothing is used by male and female. In terms of the clothing of the male, it expresses the local climate condition by the white colour and the light materials whereas the female clothing indicates the religion background which force her to wear clothing which has to cover all of her body (Al-Ajmi et al., 2008). The colour of the insulation, however, is an optional task, but it has to be highlighted that based on traditional and Islamic factors 'Black' colour is the most common colour in Saudi Arabia which observe the heat significantly during the day time.

\section{Skin Temperature}

It can be classified as part of the insulation that protects the body from the surrounding environment. Human's skin is composed of three main parts the surface of the skin, shell and the core (Sakka et al., 2012), please check Fig. 4 which indicate the local thermal discomfort.

Changing the core temperature is more difficult than changing the skin surface temperature in triggering physiological point of view (Bulcao et al., 2000). Furthermore, the core temperature is the part that needs to remain at $37^{\circ} \mathrm{C}$ otherwise the body could be under a 
risk (Fig. 6 and 7). Sakka et al. (2012) has reported that if the body become hot, blood flows through the dermis to release heat through the epidermis. Moreover, if the body was too hot and extra heat has to be taken, then the surface of the skin is moistened with sweat for evaporation hence cooling the skin.

As we go deeper in the skin surface, the effect of the temperature becomes smaller. Skin and shell temperature, for instance, could vary with respect to the external environment condition. In contrast, the trunk of the skin or what can be called the core temperature, does not have that much of fluctuation, that is way foots and hands vary considerably and could have much lower or higher temperature from the core (Sakka et al., 2012).

\section{Gender Consideration}

It is quite common that male and female has to work or be at the same place with the same condition. This could result to inconvenience for one of them or even both in some cases. Many researchers have shown that there are some differences between male and female in terms of thermal comfort. They all agree on the fact that female was found to feel more comfortable at higher temperature than male.

Karjalainen (2007) and Parsons (2002) have indicated in his study which was focusing in gender differences in thermal comfort in everyday thermal environment, he found that woman prefer higher temperature than male, especially, in office buildings where the internal environment considerably high.

Wang (2006) also has agreed on the same view where he specified the prefer difference between them by $1^{\circ} \mathrm{C}$ (20.9 for males and 21.9 for female). He is arguing that the differences between men and women in terms of thermal comfort vary from one condition to another and from type of building to another. This view also has been supported by a study done by Choi et al. (2010). The study states that female are more dissatisfied with their thermal environment than males, particularly, in summer time. In contrast, Parsons (2002) believes that there is no significant differences between male and female, all the matter is that female are more sensitive to temperature. This could be more like in the other aspects, where female tend to have more sensitivity upon anything (Sakka et al., 2012).


Fig. 7. Simple structure of human skin; Actual and complete structure of human skin. Source: Parsons (2002) 


\section{Adaptive Thermal Approaches}

Human body try to maintain a comfortable environment by physiological process such as sweating or shivering (MACQUARIE, 2004). Moreover, they are always in chase to achieve thermal comfort in their environment (HSE, 2012) and they would use many strategies to obtain satisfaction (Liu and Humphecys, 2002). The adaptive principle can be defined as "If $a$ change occurs such as to produce discomfort, people react in way which tend to restore their comfort" (Liu and Humphecys, 2002; Liu et al., 2012; Sing et al., 2011; MACQUARIE, 2004). People have natural ability to adaptive comfort under various conditions. It has to be considered that the strategies of adaptation for people have been developed significantly. In addition to that designers have not paid attention to sustainability in their projects as a part of their responsibility. It might be because they did not realise its importance. However, the concept of building design has changed to provide more comfortable indoor environment for users (Liu and Humphecys, 2002).

Some researchers argued that adaptive thermal comfort can be classified into three main categories as following: 1. Physiological adaptation, 2. Psychological adaptation and 3.Behavioural adaptation. Physiological adaptation can be considered as a controller of thermal human body. Consequently, the react to the environment condition is actually a physiological response. As far as psychological adaptation is concerned, there is no a clear explanation of this aspect as such. Moreover, there is no obvious observation out of this element as it is quite complicated (Choi et al., 2010) (Fig. 10).

Finally, behavioural adaptation which expresses all the acts that taken by individual whether that act was consciously or unconsciously. It comprise of three major elements personal level which involve changing clothes for instance, technological level such as opening or closing windows and cultural adjustment, for example, having a little nap in extreme hot day (Sing et al., 2011; Choi et al., 2010). Liu et al. (2012) has pointed out that behavioural adaptation can be accepted as the most observable aspect in user's life. This might clarified the various reactions that can be expected from individuals that come from different background (Choi et al., 2010). This could give a more illustrations with regard to the increase in behavioural adaptation in summer for most of people and limited in higher economic assembles (Indraganti, 2011).

Other researchers are of the opinion that there are different aspects that might be responsible for achieving adaptive thermal comfort. For instance, Liu et al. (2012) has highlighted clothing, taking hot or cold drinks and running cooling and heating units as variable affecting adaptive thermal comfort.

Moreover, Indraganti (2011) has added personal environmental controls, metabolism and behavioural control actions to the previous list.

With regard to the most effective aspects in adaptive thermal comfort, researchers have pointed out several elements (Fig. 8). Climate is one of the prime contextual variables where outdoor temperature is plying the major role (Mui and Chan, 2003). In addition to that (MACQUARIE, 2004) has added the second major context which is building design and time within the course of the year came at the end of the list. This representing summer, autumn, winter and spring. Furthermore, clothing has a large potential for adaptive thermal comfort, when proper selection of clothing is made for each time and season. This will ensure massive adaptive in thermal comfort and make it easier for people to achieve comfort level (Sing et al., 2011). One more point that has to be highlighted is natural ventilation. It has been observed that natural ventilation has the ability to change thermal comfort level indoors with steady indoor temperature (ASHRAE-55, 2004; Schweiker et al., 2012).



Fig. 8. The main aspects effecting thermal comfort and other additional common aspects that leading to the actual state of thermal comfort 

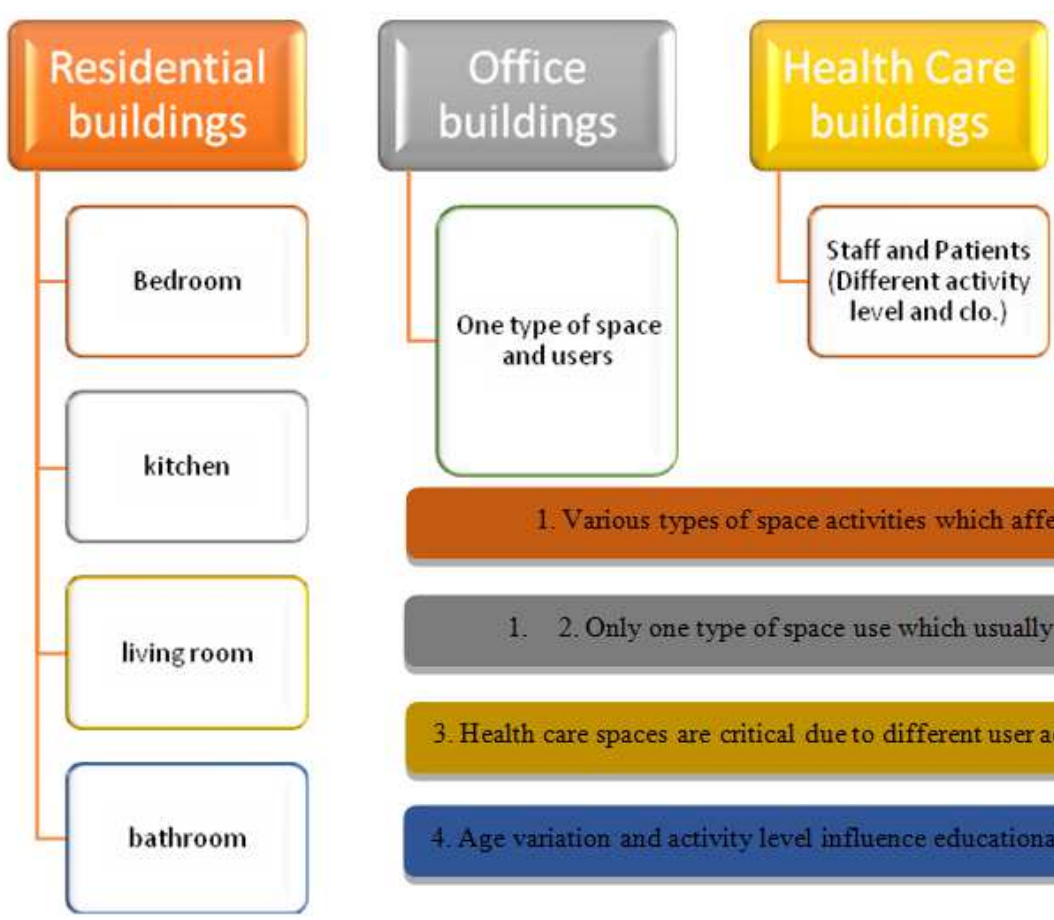

Educational buildings



\section{Various types of space activities which affect the themal adaptation}

1. 2. Only one type of space use which usually be the form of open space

3. Health care spaces are critical due to different user activities and clothing level

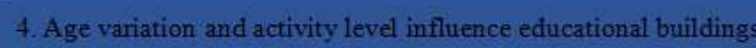

Fig. 9. Effect of building function on adaptive thermal comfort

In fact, it seems that there is a strong correlation between choosing the right cloth, indoor temperature and air velocity in adaptive thermal comfort (Nguyen et al., 2012).

\section{Effect of Building Function on Adaptive Thermal Comfort}

Articles can be classified based on different building types and function (Peeters et al., 2009). The function and use of a building can make a massive difference in terms of the opportunity of adaptive thermal comfort for occupancy. Four main buildings types will be taken into consideration:

- $\quad$ Residential buildings

- Office building

- Healthcare buildings

- $\quad$ Educational buildings (Fig. 9)

Each one of these buildings has its own use, activity and variety of zones which all will have certain effect on chance of adaptation.

\section{Residential Buildings}

It is one of the most energy consumption comparing with the other types of buildings (Ghisi and Massignani, 2007). This might be because of the amount of time that people spend in their homes. In addition,
Djongyang et al. (2010), has drawn attention to the fact that residential buildings consist of several kind of spaces such as living room, bedroom and kitchen and each one of them require its own thermal comfort level.

In a study done by Peeters et al. (2009) which express that thermal comfort in residential buildings rely heavily on local weather. There are three explanations for this. The first one is because most of people in developing countries live in rural areas (Schweiker et al., 2012). The second justification is that many people live in detach house which leave all the external walls and ceiling expose to the fluctuation of the weather. The third one as it has been considered by (Ghisi and Massignani, 2007) which indicates the importance of dwelling thermal performance which leads to increase in energy consumption. As a result, it has to be highlighted that the energy consumption of domestic buildings has to be reduced, especially, in the rapid rise of residential buildings.

In a work done by Peeters et al. (2009), where he has divided residential building into three main zones; each one has different requirement of thermal comfort and these as following: Bathroom, bedroom and other rooms such as kitchen, living room, study room and etc. Furthermore, Peeters has pointed out the reason of such classifications which based on physical activity level and more individual factors that will be discussed later within the paper. For instance, in bathroom there are air temperature of the water of the bath, air temperature of the bathroom and humidity of air (Zingano, 2001). 
Moreover, Peeters et al. (2009) has observed that bathrooms have a very critical lower limit temperature due to the condition of the body (nude) and wetness (humidity). He has state the comfort in the bathroom in the range from $\left(21\right.$ to $\left.30.5^{\circ} \mathrm{C}\right)$.

There is a far more published papers have been done on bathrooms when considering variety of zones in residential building. As a result, more attention will be given to it.

\section{Bedrooms}

People spend one-third of their life sleeping (Djongyang et al., 2010). This includes every single human being. Furthermore, to surpass tiredness, sleeping might be a good solution. Consequently, there should be abundance in research on this field. However, as the author has pointed out that there are quite limited publications. One of the most important factors in sleeping thermal adaptation that should be taken into consideration is that behavioural adaptation is limited during sleep (Schweiker et al., 2012). Traditional matters might have an effect on sleepwear. For instance, the traditional style bed of Chinese which called "Zonghang" provide less insulation (Lin and Deng, 2008). In addition to that people may prefer sitting or sleeping on floor rather than sofas or beds, respectively (as it is the case in Eastern style). This could raise certain limitations (Maerefat et al., 2012).

In a paper conducted by Lin and Deng (2008) where values of the bedding system has been divided into the following: bed, bedding (its percentage covering over human body) and sleepwear. The overall thermal insulation value of the bedding has a major impact on thermal comfort. Furthermore, another study done by Lin and Deng (2006) is supporting this fact where a survey has been conducted. It shows that most of people prefer cooler indoor temperatures at sleeping time (below $24^{\circ} \mathrm{C}$ ). It has to be highlighted that bedding system has to be taken into consideration in energy balance to provide thermal comfort in different indoor environments (Djongyang et al., 2012).

\section{Office Buildings}

Deep plan in office buildings started to appear since 1960s (Fig. 11) with fully glazed façade that would increase the need for artificial lights. Moreover, in 1980s personal computers compensated pen as well as typewriter which added extra heat. Even though in moderate climates, these extra loads would not be easily removed by natural ventilation (Djongyang et al., 2012). As a result, energy consumption in office buildings is mainly used for creating and maintaining comfort conditions in the internal environment (Ghisi and Massignani, 2007). In addition, Hens (2009) has expressed that air conditioning in office building is on operation in North Western Europe as a result of high internal loads created by personal computers as well as solar gain.

Many researchers have expressed the fact that office buildings experience maximum energy consumption as they rely usually on mechanical methods to achieve thermal comfort. In a study conducted by Chen and Chang (2012), which observes that over-cooling, is typical in office buildings this is due to adaptation and design of air conditioning system. However, Barlow and Fiala (2007) is against this in a paper done in UK's offices where a group of people has voted for opening windows as their favorite method for achieving thermal comfort. However, this contrast might have some additional aspects involved such as local location; location like the UK dose not experience extreme summer like other locations does, with exception of some heat-waves that take place in summer.

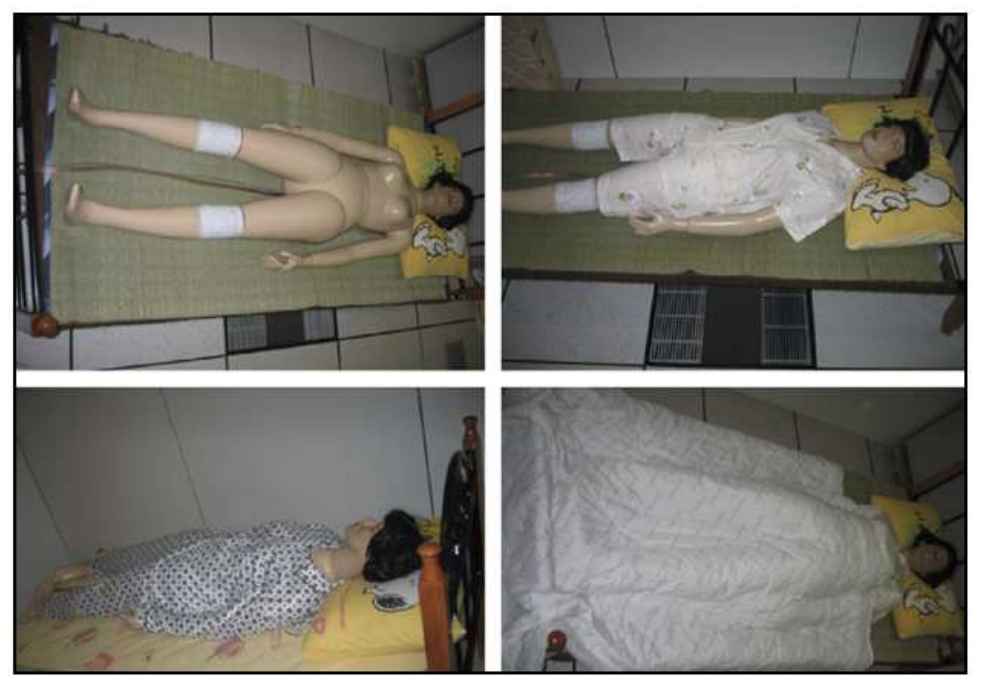

Fig. 10. Examples of experiment of sleeping conditions with different level of clothing insulation. Source: Lin and Deng (2008) 


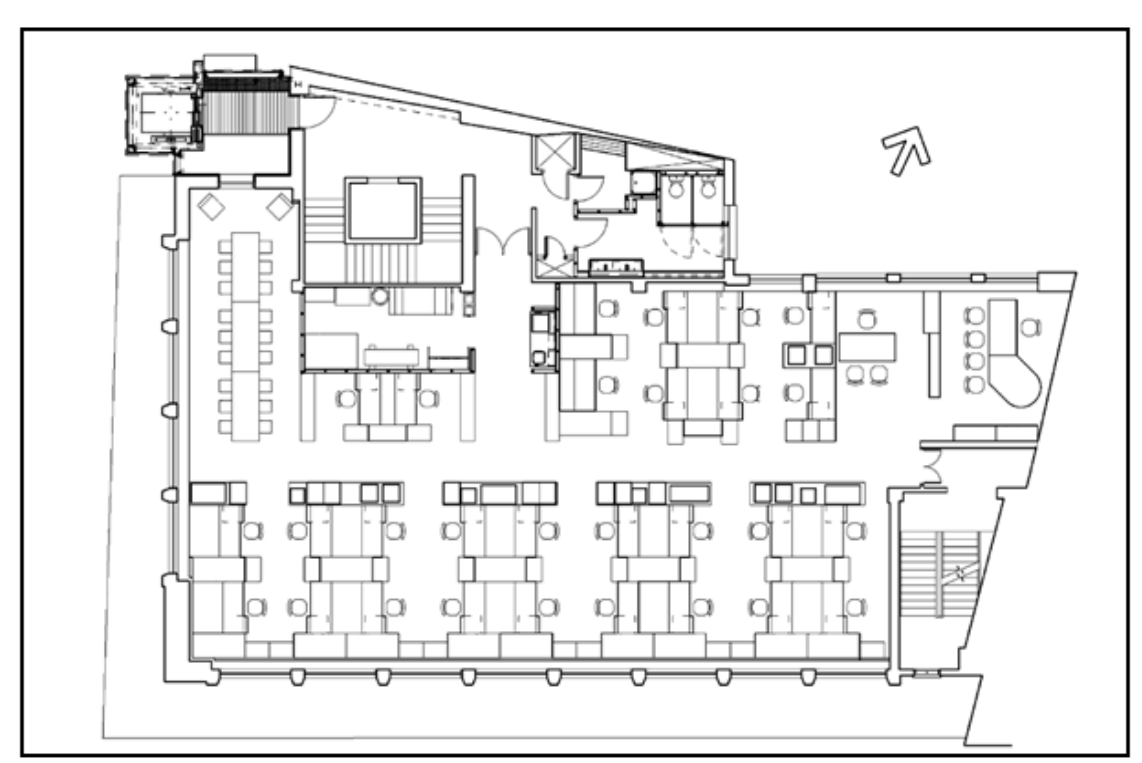

Fig. 11. Typical office floor plan. Source: Barlow and Fiala (2007)

One of the most elements that make it difficult for workers in office buildings to achieve thermal comfort is that they do not change their clothing during the day. Such method which considered as one of the active thermal adaptation is quite important to reduce energy consumption in office buildings (Barlow and Fiala, 2007). Furthermore, Ricciardi and Buratti (2012) has shared the same opinion. He mentioned that in hot and arid climate, clothing insulation has a significant impact on thermal comfort on office workers.

There are several active approaches that may result a massive reduction in energy consumption in office buildings:

- Temporal and spatial control (workers changing their time to avoid inconvenience working conditions)

- $\quad$ Adding or removing cloths based on the current condition

- $\quad$ Solar shading control (to reduce solar gain)

- Switching off the lights which it is not needed

- Natural ventilation control (opening and closing windows) (Barlow and Fiala, 2007)

It has to be mentioned that adaptive approaches will always give different results due to the variation of subjective behavior of the workers and their background (Ricciardi and Buratti, 2012). In a study done by Han et al. (2016) where he introduced two new systems (XT-DOAS) and (CwRsys) which aid to reduce indoor air temperature. The first system managed to save $15.6 \%$ of annual energy use for air conditioning as compared with the later one. Moreover, another technique which has investigated by Sabrina and
Souuthall (2015) which expresses the advantage of utilizing double skin façade, which considered as a part of natural ventilation system, in order to achieve thermal comfort in office buildings. The study reveal that this strategy is able to provide roughly $70 \%$ of occupant's hour within comfort level.

All in all, satisfaction in any type of building, including office buildings is subject to various reasons such as background and enlightenment satisfaction in a certain microclimate. In a study conducted by Julia and David (2015) where two groups were tasted based on occupant knowledge of passive design system and environmental satisfaction. The study concluded that those who had received effective training was found more likely to be satisfied that those who did not. In addition to that, the work of Shady and Salvatore (2015) which was carried out in office buildings in Japan has shown that users can remain comfortable with indoor air temperature under $28^{\circ} \mathrm{C}$. This support findings of such research which reveal that universal index such as PMV might be misleading when compared with actual state of thermal comfort (Ali et al., 2015).

\section{Health care Buildings}

Healthcare is a wide term that covers any building which its main purpose is to take care of people's health including hospitals, GPs and etc (Fig. 12 and 13). Since hospitals are the most common destination for patients, it will be highlighted only representing health care buildings. Hospitals have been classified as one of the most complex internal environment with wide range of facilities and numerous different users. Furthermore, it has the most demanding indoor zones. 


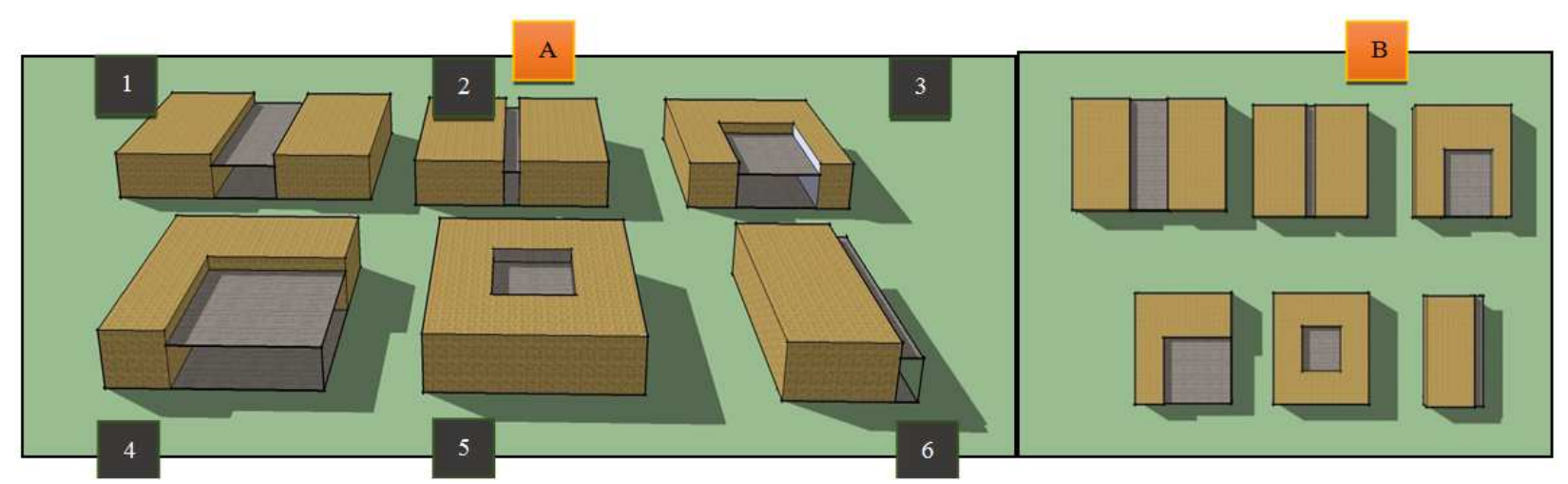

Fig. 12. Classification of most common school building forms (reproduced with some modifications from Graca 2007); (A) 3D views of each form of school building; 1 . Two sets sequence of classrooms with corridor; 2. Double loaded corridor plane; 3. "U" shape of classrooms around semi closed courtyard; 4. "L" shape of classrooms; 5. Classrooms opened on a fully closed courtyard; 6 . Row of classrooms along a single corridor; (B) Top views of the same forms of the schools placed in the same order

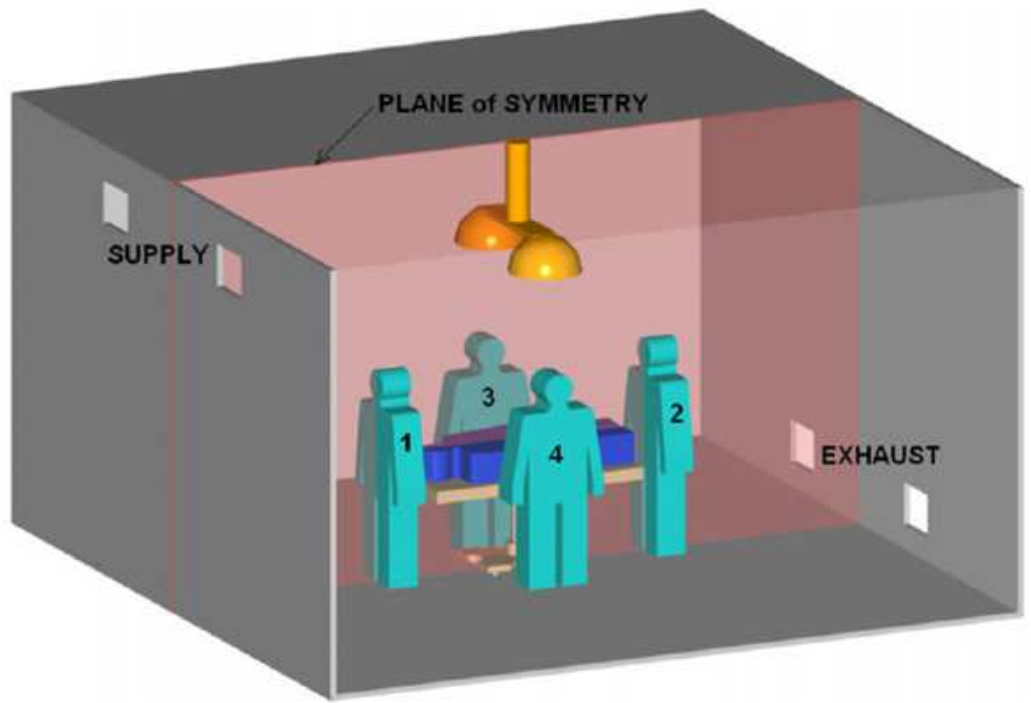

Fig. 13. Model of an operation room in a hospital

Maintaining a fixed internal condition in hospitals is very critical which has to be in operation $24 \mathrm{~h}$ every day. These statistics are making it the highest energy consumption per unit floor area in the entire buildings sector (Hwang et al., 2007).

Observing a patient's illness does not only know his or her body temperature as a result of weakness, but it rather understands that creating comfort environment would be beneficial to stabilize moods of patients (Khodakarami and Nasrollahi, 2012). Although there has been a various publications on thermal comfort, but most of them did not take hospitals into consideration (Skoog et al., 2005).

As far as the difficulties of adaptive thermal comfort in hospitals are concerned, there is a significant difference between patient and staff in their conception among thermal comfort due to the differential in range of activities, cloths and medical condition. On the top of that physical, social and individual needs of each one of the two groups vary to far extent. Moreover, patients usually have lower activities when comparing with staff, because they have to remain on bed as long as they are in the hospitals in many cases. As a result, all these variables make it quite hard to optimize and achieve thermal comfort for both of them (Balaras et al., 2007).

Operation room in hospitals is the most critical zone where indoor air temperature, humidity and air velocity has to be kept within a certain range. Consequently, it requires a sufficient HVAC installed to provide very high demand indoor environment (Ho et al., 2009a).

He found that it is more effective placing the supply grilles closer to the vertical centerline of the wall. In 
addition, in such zones, there is still the need for natural ventilation even in winter time when the mean of natural ventilation become very limited. Adamu et al. (2012) has revealed that $25 \%$ ducts ventilation opening fraction is needed to achieve required air flow rates and convenience thermal comfort in winter. Hashiguchi et al. (2008) has expressed the need for increase the humidity in winter which caused by the use of central heating systems. In fact, low relative humidity could have an effect not only on comfort, but also on health. Furthermore, humidifiers in hospitals during winter time can have a major impact in increasing humidity, with exception to large open space such as nurse-station.

Finally, peak times should receive enough consideration, in terms of hospitals; it was found that morning time is the issue in winter and noon in summer (Corgnati et al., 2007).

\section{Educational Buildings}

Thermal comfort has a significant impact on student's performance (Mumovic et al., 2009; Zeiler and Boxem, 2009; Teli et al., 2012). The importance of insuring acceptable indoor air quality in class rooms is distinguished as contributed factor to the learning performance of students (Ho et al., 2009b). Moreover, providing healthy and comfortable environment is crucial for every single type of buildings, particularly, in schools where a high level of indoor condition quality is important to enable them to spend many time of listening and understanding their lessons without any moment from the desks (Balaras et al., 2007). As a result, the condition in class rooms should be improved in an urgent educational preference (Nor et al., 2015), as it is the case for the improvement of indoor air quality in class rooms (Chen and Chang, 2012).

The most affected categories in schools are children in the range of age from 7 to 11 . Those have very limited chance for thermal adaptation for many explanations (Aiman et al., 2015; Noppauch et al., 2015; Antonio et al., 2016). For this reason, more focus will be on them. Two main problems face children to adapt properly:

- Cloths

- Activity level

In terms of cloths, some of young students go to school in the early morning wearing thicker cloth because of the cool air at that time. However, they get warmer in the noon time because they usually do not remove any of these cloths (Pourshaghaghy and Omidvari, 2012). Furthermore, Teli et al. (2012) and Humphreys (1977) have drawn attention to the same factors which lead to different perceived optimal conditions, hence would have a warmer thermal sensation than adults.
With regard to activity level, students have to remain settled during lessons. Consequently, adjusting and modifying their activity level will be limited. This kind of freedom may also include adding or taking off some cloths, opening or closing windows or even modifying sun-shading devices (Balaras et al., 2007).

The integration between natural ventilation and thermal comfort level in school building should receive certain consideration since it may result noise that derives from internal environment. For instance, Mumovic et al. (2009) stated that in many cases, proper ventilated school building often result an increase of negative impact on students. He observed that there is a serious challenge to integrate thermal comfort, ventilation and acoustics which, perhaps, make it more difficult for the designers to pay more attention toward this matter.

However, other believes that adaptation in school building is primarily. Adamu et al. (2012) highlighted that individuals in school buildings has their feelings and response to the internal environmental condition. In addition to that, Noppauch et al. (2015), comfort can be obtained by only increasing air speed to high indoor universally acceptable temperatures such as 26,27 or $28^{\circ} \mathrm{C}$.

There are so many buildings which did not mentioned in the above categories due to limitation of research and priority. For instance, there are historic buildings (Ricardo et al., 2016), theatre buildings (Nowak-Dzieszko and Rojewska-Warchał, 2015), universities (Sanjay et al., 2016) and laboratories spaces (Xiaoyu et al., 2014) which both can be classified as educational type of building.

\section{Conclusion}

This paper presents a literature review on thermal comfort. There was more focus on buildings and the properties of it such as zones available and types of users. One of the most problems for archiving thermal comfort in buildings is disregarding the impact of different types of building use. As a result, this review is leading to seek a solution for this problem which usually found neglected.

Thermal comfort estimation approaches have been taken into consideration where two main methods were demonstrated PMV and PPD. It has been mentioned that these are the most common and accepted methods to predict the state of user in terms of thermal comfort. Moreover, both of them rely heavily on six main aspects. Some of which could be considered as environmental elements such as air temperature, radiant temperature, humidity whereas the other two can be classified as personal elements such as metabolic rate (activity) and clothing insulation. These factors have a considerable impact on the actual state of thermal comfort for the users. However, there are some other personal aspects that could have certain contribution as well. For instance, 
two users could be setting in the same internal condition, at the same time, but they might have completely different thermal comfort.

In general, environmental aspects seem to have the most effective points that could influence the state of thermal comfort for individuals. Moreover, air temperature is the most effective one among the rest. It is the key factor that concern people when considering a new place. However, people can accept wider range of temperature even above the optimum that suggested by Fanger which is 25.6 when addressing adaptation which can bring the average to higher or lower levels. It also has to be highlighted that there is a very strong relationship between air temperature, relative humidity and air speed to allow the skin to loss heat in by sweating in the case of higher temperature. Furthermore, activity which is known by metabolic rate also could have a massive influence on human thermal comfort, particularly; in the case of addressing different types of building since each building has its own purpose (function) and also its own required activity. For instance, there is a clear difference in the activity level between school where student usually remain seated and between their teachers who has to be standing and moving most of the time.

Heat loss and gain has also been discussed within the review and has given certain consideration. Heat loss and gain is the incident of heat exchange with the surrounding environment through the envelope of the building which could be walls, floors, roofs, glazing and so on. It has a strong relationship with thermal comfort as it affects the state of the users directly. In can be agreed that such knowledge can serve to predict the influence if the outdoor environment as well as the envelope of the building to cop which will have a significant impact on users. It has to be mentioned that heat loss and gain through glazing has a remarkable influence on the incident of change heat with outdoor environment and that rely on three main aspects the size of the window, the direction and the U-value of the glazing.

The effect of building function on adaptive thermal comfort has been discussed with reference to residential, office, healthcare and educational buildings. It has to be considered that there is a noticeable effect on the different types of building in terms of its impact on the users.

Residential building, for instance, is consist of four main zones living room, bedroom, kitchen and bathroom and each one has its own requirement of thermal comfort in terms of needed indoor temperature, humidity and air velocity. In bedrooms there is an additional insulation aspect which is the sleepwear. This makes most of the users prefer lower indoor temperature in bedrooms. On the other hand, high indoor temperature is preferred in bathroom where the user wear there less cloth, or even to be naked. Moreover, in the kitchen there is extra heat that derived from the mechanical equipment there.

The characteristics of modern office building design has been introduced which has deep plans, glazed façade and personal computers which is responsible of the extra heat that is common in office buildings todays. All these make it quite difficult to cool the space with minimum reliance on mechanical equipment such as heating or cooling.

In hospitals there are serious challenges. The combination of the users which represented in patients and staff make it very difficult to achieve thermal comfort. Each of them has different activities and also different clothing. Hospitals classified as the highest energy consumption sector by meter squire when comparing with other types of buildings as there are many equipment and facilities which have to be in operation $24 \mathrm{~h}$. In addition, operation rooms are one of the most critical zones in the list. It requires more attention and research to maintain a fixed indoor condition in the existing of much equipment.

The importance of insuring acceptable indoor air quality in classrooms is distinguished as contributed factor to the learning performance of students. It quite essential to clarify that the most affected categories in school buildings are children in the age of (7 to 11). Children in such age found with limited chance for thermal adaptation such as changing cloth and activity level where students have to remain seated on their chairs. The integration between natural ventilation and thermal comfort level in school buildings has been found very complicated since the "noise" is essential in such buildings. More research and investigation is required to address this issue which can help to provide more sustainable and comfortable environment for students.

Although types and function of building is essential to ensure acceptable indoor environment, some other aspects and techniques are also important such as behaviour of occupants, early stage of design, importance of natural ventilation and much more (Humphreys, 1977).

\section{Declaration of Conflicting Interest}

The author declared no optional conflicts of interest with respect to the research, authorship and/ or publication of this article.

\section{References}

Adamu, Z., A. Price and M. Cook, 2012. Performance evaluation of natural ventilation strategies for hospital wards-a case study of Great Ormond Street Hospital. J. Build. Environ., 56: 211-222.

DOI: 10.1016/j.buildenv.2012.03.011 
Aiman, A., A. Dariusz, A. Page and B. Moghtaderi, 2015. Assessment of the thermal performance of complete buildings using adaptive thermal comfort. Proc. Soc. Behav. Sci., 216: 655-661. DOI: $10.1016 /$ j.sbspro.2015.12.051

Al-Ajmi, F., D. Loveday, K. Bedwell and G. Havenith, 2008. Thermal insulation and clothing area factors of typical Arabian Gulf clothing ensembles for males and females: Measurements using thermal manikins. J. Applied Ergonom., 39: 407-414.

DOI: 10.1016/j.apergo.2007.10.001

Ali, A., B. Faisal and B. Read, 2015. Thermal comfort assessment of an office building served by UnderFloor Air Distribution (UFAD) system-a case study. J. Build. Environ., 85: 153-1599.

DOI: $10.1016 /$ j.buildenv.2014.11.027

Antonio, M., A. Isabel, C. Soolyeon and V. Jose-Luis, 2016. Energy efficiency and thermal comfort in historic buildings: A review. J. Renewable Sustainable Energy Rev., 61: 70-85.

DOI: $10.1016 /$ j.rser.2016.03.018

ASHRAE-55, 2004. Thermal environment conditions for human occupancy. ASHARAE.

Atmaca, I., O. Kaynkli and A. Yigit, 2007. Effects of radiant temperature on thermal comfort. J. Build. Environ., 42: 3210-3220.

DOI: $10.1016 /$ j.buildenv.2006.08.009

Backer, R. and M. Paciuk, 2009. Thermal comfort in residential buildings-failure to predict by standard model. J. Build. Environ., 44: 948-960. DOI: 10.1016/j.buildenv.2008.06.011

Balaras, C., E. Dascalaki and A. Gaglia, 2007. HVAC and indoor thermal conditions in hospital operating rooms. J. Energy Build., 39: 454-470. DOI: 10.1016/j.enbuild.2006.09.004

Barlow, S. and D. Fiala, 2007. Occupant comfort in UK offices-how adaptive comfort theories might influence future low energy office refurbishment strategies. J. Energy Build. 39: 837-846. DOI: 10.1016/j.enbuild.2007.02.002

Bulcao, C., S.M. Frank, S. Raja, K. Tran and D.S. Goldstein, 2000. Relative contribution of core and skin temperatures to thermal comfort in humans. J. Thermal Biol., 25: 147-150. DOI: $10.1016 / \mathrm{S} 0306-4565(99) 00039-X$

Caril, M., B. Olesen, A. Zarrella and R. Zecchim, 2007. People's clothing behaviour according to external weather and indoor environment. J. Build. Environ., 42: 3965-3973.

DOI: $10.1016 /$ j.buildenv.2006.06.038

Chen, A. and V. Chang, 2012. Human health and thermal comfort of office workers in Singapore. J. Build. Environ., 58: 172-178.

DOI: 10.1016/j.buildenv.2012.07.004
Cheong, K., E. Djunaedy, Y. Chya, K. Tham and S. Sekhar et al., 2003. Thermal comfort study of an air-conditioned lecture theatre in the tropics. J. Build. Environ., 38: 63-73. DOI: $10.1016 / \mathrm{S} 0360-1323(02) 00020-3$

Choi, J., A. Aziz and V. Loftness, 2010. Investigation on the impacts of different genders and ages on satisfaction with thermal environments in office buildings. J. Build. Environ., 45: 1529-1535. DOI: 10.1016/j.buildenv.2010.01.004

Corgnati, S., M. Filippi and S. Viazzo, 2007. Perception of the thermal environment in high school and university classrooms: Subjective preferences and thermal comfort. J. Build. Environ., 42: 951-959. DOI: $10.1016 / j$.buildenv.2005.10.027

Djongyang, N., R. Tchinda and D. Njomo, 2010. Thermal comfort: A review paper. J. Renewable Sustainable Energy Rev., 14: 2626-2640. DOI: $10.1016 /$ j.rser.2010.07.040

Djongyang, N., R. Tchinda and D. Njomo, 2012. Estimation of some comfort parameters for sleeping environments in dry-tropical sub-Saharan Africa region. J. Energy Convers. Manage., 58: 110-119. DOI: 10.1016/j.enconman.2012.01.012

Ghisi, E. and R. Massignani, 2007. Thermal performance of bedrooms in a multi-storey residential building in Southern Brazil. J. Build. Environ., 42: 730-742. DOI: 10.1016/j.buildenv.2005.10.026

Hall, D., S. Walker and A. Spanton, 1999. Dispersion from courtyards and other enclosed spaces. J. Atmos. Environ., 33: 1187-1203.

Hall, R., 2010. Materials for Energy Efficiency and Thermal Comfort in Buildings. CRC, UK.

Han, L., W. Lee and J. Jie, 2016. Applying a novel extralow temperature dedicated outdoor air system in office buildings for energy efficiency and thermal comfort. J. Energy Convers. Manage., 121: 162-173. DOI: 10.1016/j.enconman.2016.05.036

Hanqing, W., H. Chunhue, L. Zhiqiang and T. Guangfa, 2006. Dynamic evaluation of thermal comfort environment of air-conditioned buildings. J. Build. Environ., 41: 1522-1529.

DOI: $10.1016 /$ j.buildenv.2005.06.002

Hashiguchi, N., M. Hirakawa, Y. Tochihara, Y. Kaji and C. Karaki, 2008. Effects of setting up of humidifiers on thermal conditions and subjective responses of patients and staff in a hospital during winter. J. Applied Ergonom., 39: 158-165.

DOI: $10.1016 /$ j.apergo.2007.05.009

Hens, H.S.L.C., 2009. Thermal comfort in office buildings: Two case studies commented. J. Build. Environ., 44: 1399-1408. DOI: 10.1016/j.buildenv.2008.07.020 
Ho, S., L. Rosario and M. Rahman, 2009a. Threedimensional analysis for hospital operating room thermal comfort and contaminant removal. J. Applied Thermal Eng., 29: 2080-2092. DOI: $10.1016 /$ j.applthermaleng.2008.10.016

Ho, S.H., L. Rosario and M.M. Rahman, 2009b. Thermal comfort enhancement by using a ceiling fan. J. Applied Thermal Eng., 29: 1648-1656. DOI: 10.1016/j.applthermaleng.2008.07.015

Homod, R., K. Sahari, H. Almurib and F. Nagi, 2012. RLF and TS fuzzy model identification of indoor thermal comfort based on OMV/PPD. J. Built Environ., 49: 141-153.

Hoof, J.V. and J.L.M. Hensen, 2007. Quantifying the relevance of adaptive thermal comfort models in moderate thermal climate zones. J. Build. Environ., 42: 156-170.

DOI: $10.1016 /$ j.buildenv.2005.08.023

HSE, 2012. The six basic factors. Health and Safety Executive.

Humphreys, M.A., 1977. A study of the thermal comfort of primary school children in summer. J. Build. Environ., 12: 231-239. DOI: 10.1016/0360-1323(77)90025-7

Hwang, R.L., T.P. Lin, M.J. Cheng and J.H. Chien, 2007. Patient thermal comfort requirement for hospital environments in Taiwan. J. Build. Environ., 42: 2980-2987.

DOI: $10.1016 /$ j.buildenv.2006.07.035

Indraganti, M., 2011. Thermal comfort in apartments in India: Adaptive use of environmental controls and hindrances. J. Renewable Energy, 36: 1182-1189. DOI: $10.1016 /$ j.renene.2010.10.002

ISO-7730, 2005. Ergonomics of the thermal environment-analytical determination and interpretation of thermal comfort using calculation of the PMV and PPD indices and local thermal comfort criteria. ISO.

Jang, M.S., C.D. Kol and I.S. Moon, 2007. Review of thermal comfort design based on PMV/PPD in cabins of Korean maritime patrol vessels. J. Build. Environ., 42: 55-61.

DOI: 10.1016/j.buildenv.2005.07.025

Julia, D. and G. David, 2015. Understanding high performance buildings: The link between occupant knowledge of passive design systems, corresponding behaviours, occupant comfort and environmental.

Karjalainen, S., 2007. Gender differences in thermal comfort and use of thermostats in everyday thermal environments. Build. Environ., 42: 1594-1603.

DOI: 10.1016/j.buildenv.2006.01.009
Khodakarami, J. and N. Nasrollahi, 2012. Thermal comfort in hospitals-a literature review. J. Renewable Sustainable Energy Rev., 16: 4071-4077. DOI: $10.1016 /$ j.rser.2012.03.054

Kuchen, E. and M.N. Frsch, 2009. Spot monitoring: Thermal comfort evaluation in 25 office buildings in winter. J. Build. Environ., 44: 839-847. DOI: 10.1016/j.buildenv.2008.06.023

Lee, J.Y. and J.W. Choi, 2004. Influences of clothing types on metabolic, thermal and subjective responses in a cool environment. J. Thermal Biol., 29: 221-229. DOI: 10.1016/j.jtherbio.2004.02.006

Lin, Z. and S. Deng, 2006. A questionnaire survey on sleeping thermal environment and bedroom air conditioning in high-rise residences in Hong Kong. J. Energy Build., 38: 1302-1307. DOI: $10.1016 /$ j.enbuild.2006.04.004

Lin, Z. and S. Deng, 2008. A study on the thermal comfort in sleeping environments in the subtropics- Measuring the total insulation values for the bedding systems commonly used in the subtropics. Build. Environ., 43: 905-916. DOI: 10.1016/j.buildenv.2007.01.027

Liu, J., R. Yao and R. McCloy, 2012. A method to weight three categories of adaptive thermal comfort. Energy Build., 47: 312-320. DOI: $10.1016 /$ j.enbuild.2011.12.007

Liu, J.F. and M.A. Humphecys, 2002. Adaptive thermal comfort and sustainable thermal standards for buildings. J. Energy Build., 34: 563-572. DOI: 10.1016/S0378-7788(02)00006-3

Liu, Y., Y. Haiyan and L. Joseph, 2014. Thermal comfort and building energy consumption implications-a review. Applied Energy, 115: 164-173. DOI: 10.1016/j.apenergy.2013.10.062

MACQUARIE, 2004. the adaptive model of thermal comfort. MACQUARIE.

Maerefat, M., A. Zolfaghari and A. Omidvar, 2012. On the conformity of floor heating systems with sleeping in the eastern-style beds; physiological responses and thermal comfort assessment. Build. Environ., 47: 322-329.

DOI: 10.1016/j.buildenv.2011.07.008

Memon, R.A., S. Chirarattananon and P. Vangtook, 2008. Thermal comfort assessment and application of radiant cooling: A case study. Build. Environ., 43: 1185-1196. DOI: 10.1016/j.buildenv.2006.04.025

Metje, N., M. Sterling and C. Baker, 2008. Pedestrian comfort using clothing values and body temperatures. J. Wind Eng. Indust. Aerodynam., 96: 412-435. DOI: 10.1016/j.jweia.2008.01.003 
Mui, K.W.H. and W.T.D. Chan, 2003. Adaptive comfort temperature model of air-conditioned building in Hong Kong. J. Build. Environ., 38: 837-852. DOI: 10.1016/S0360-1323(03)00020-9

Mumovic, D., J. Palmer, M. Davies, M. Orme and I. Ridley et al., 2009. Winter indoor air quality, thermal comfort and acoustic performance of newly built secondary schools in England. Build. Environ., 44: 1466-1477.

DOI: 10.1016/j.buildenv.2008.06.014

Mustapa, M.S., S.A. Zaki, H.B. Rijal, A. Hagishima and M.S.M. Ali, 2016. Thermal comfort and occupant adaptive behaviour in Japanese university buildings with free running and cooling mode offices during summer. Build. Environ., 105: 332-342.

DOI: $10.1016 /$ j.buildenv.2016.06.014

Nguyen, A.T., M.K. Sing and S. Reiter, 2012. An adaptive thermal comfort model for hot humid South-East Asia. Build. Environ., 56: 291-300.

DOI: 10.1016/j.buildenv.2012.03.021

Noppauch, P., H. Kodchasorn, B. Vorakamol and K. Joseph, 2015. A field of the thermal comfort in university buildings in Thailand under air condition room. J. Energy Proc., 79: 480-485.

Nor, A., A. Zainal and R. Wahid, 2015. Architectural evaluation of thermal comfort: Sick building syndrome symptoms in engineering education laboratories. J. Proc. Soc. Behav. Sci., 204: 19-28.

Nowak-Dzieszko, K. and M. Rojewska-Warchał, 2015. Influence of the balcony glazing construction on thermal comfort of apartments in retrofitted large panel buildings. Proc. Eng., 108: 481-487. DOI: 10.1016/j.proeng.2015.06.187

Oliveira, A., A. Gaspar and D. Quintela, 2011. Dynamic clothing insulation. Measurements with a thermal manikin operating under the thermal comfort regulation mode. J. Applied Ergonom., 1-10.

Ormandy, D. and V. Ezratty, 2012. Health and thermal comfort: From WHO guidance housing strategies. J. Energy Policy, 49; 116-121.

Parsons, K., 2002. The effect of gender, acclimation state, the opportunity to adjust clothing and physical disability on requirements for thermal comfort. J. Energy Build., 34: 593-599.

Peeters, L., R. Dear, J. Hensen and W. D'haeseleer, 2009. Thermal comfort in residential buildings: Comfort values and scales for building energy simulation. J. Applied Energy, 86: 772-780.

Pourshaghaghy, A. and M. Omidvari, 2012. Examination of thermal comfort in a hospital using PMV-PPD model. J. Applied Ergonom., 43: 1089-1095.
Ricardo, A., R. Nuno and F. Vasco, 2016. Thermal comfort models and pupils' perception in freerunning school building of a mild climate country. J. Energy Build., 111: 64-75.

Ricardo, R., V. Natalia and L. Roberto, 2015. A review human thermal comfort in the built environment. J. Energy Build., 105: 178-205.

Ricciardi, P. and C. Buratti, 2012. Thermal comfort in open plan offices in northern Italy: An adaptive approach. J. Build. Environ., 56: 314-320.

Rowe, D., 2001. Activity rates and thermal comfort of office occupants in Sydney. J. Thermal Biol., 26: 415-418.

Sabrina, B. and K. Souuthall, 2015. Thermal comfort in naturally ventilated buildings with double skin façade under tropical climate conditions the influence of key design parameters. J. Energy Build., 109: 397-406.

Sakka, A., M. Santamourise, L. Livada, F. Noicol and M. Wilson, 2012. On thermal performance of low income housing during heat waves. J. Energy Build., 49: 96-77.

Sanjay, K., S. Manoj, L. Vivan, M. Jyotirmay and M. Sanjay, 2016. Thermal comfort assessment and characteristics of occupant's behaviour in naturally ventilated buildings in composite climate of India. J. Energy Sustainable Dev., 33: 108-121.

Schweiker, M., S. Brasche, W. Bischof, M. Hawighorst and V. Karsten et al., 2012. Development and validiation of a methodology to chalange the adaptive comfort model. J. Build. Environ., 49: 336-347.

Shady, A. and C. Salvatore, 2015. Impact of different thermal comfort models on zero energy respirational buildings in hot climate. J. Energy Build., 102: 117-128.

Sing, M., S. Mahapatra and S. Atreya, 2011. Adaptive thermal comfort model for different climatic zones of North East India. J. Applied Energy, 88: 2420-2428.

Skoog, J., N. Fransson and L. Jagemar, 2005. Thermal environment in Swedish hospitals summer and winter measurements. J. Energy Build., 37: 872-877.

Talyor, P., R. Fuller and M. Luther, 2008. Energy use and thermal comfort in a rammed earth office building. J. Energy Build., 40: 793-800.

Teli, D., M. Jentsch and P. James, 2012. Naturally ventilated classrooms An assessment of existing comfort models for predicting the thermal sensation and preference of primary school children. J. Energy Build., 53: 166-182. 
Tian, L., Z. Lin, J. Liu and Q. Wang, 2011. The impact of temperature on mean local air age and thermal comfort in a stratum ventilated office. J. Build. Environ., 46: 501-510.

Wang, Z., 2006. A field study of the thermal comfort in residential buildings in Harbin. J. Built Environ., 42: 1594-1603.

Wang, Z., L. Zhang and Y. He, 2010. Thermal comfort for naturally ventilated residential buildings in Harbin. J. Energy Build., 42: 2406-2415.

Xiaoyu, D., B. Regina and D. Andy, 2014. Building microclimate and summer thermal comfort in free-running buildings with diverse spaces: A Chinese vernacular house case. J. Build. Environ., 82: 215-227.
Zeiler, W. and G. Boxem, 2009. Effects of thermal activated building systems in schools on thermal comfort in winter. J. Build. Environ., 44: 2308-2317.

Zingano, B., 2001. A discussion on thermal comfort with deduce to bath water temperature to deduce a midpoint of thermal comfort temperature zone. J. Renewable Energy, 23: 41-47. 